\title{
Healthy lifestyle factors associated with reduced cardiometabolic risk
}

\author{
L. Shi ${ }^{1 *}$, J. A. Morrison ${ }^{2}$, J. Wiecha ${ }^{1}$, M. Horton ${ }^{1}$ and L. L. Hayman ${ }^{1}$ \\ ${ }^{1}$ College of Nursing and Health Sciences, University of Massachusetts Boston, 100 Morrissey Boulevard, Boston, \\ MA O2125, USA \\ ${ }^{2}$ Cincinnati Children's Hospital Medical Center, 3333 Burnet Avenue, Cincinnati, OH 45229, USA
}

(Received 16 June 2010 - Revised 13 September 2010 - Accepted 21 September 2010 - First published online 31 January 2011)

\section{Abstract}

Minimal data are available regarding the cumulative effects of healthy lifestyle behaviours on cardiometabolic risk. The objective of the present study was to examine a combination of healthy lifestyle behaviours associated with cardiometabolic risk reduction. The analysis was based on a cross-sectional study of 1454 participants from the population-based Lipid Research Clinic's Princeton Follow-up Study. The healthy lifestyle factors included fruit and vegetable intake $\geq 5$ servings/d, meat intake $\leq 2$ servings/d, never smoking, consuming 2-6 alcoholic drinks/week, television (TV) viewing time $\leq 2 \mathrm{~h} / \mathrm{d}$ and moderate to vigorous physical activity $\geq 4 \mathrm{~h} /$ week. The combination of healthy lifestyle behaviours was strongly and negatively associated with the presence of cardiometabolic risk, as well as with a composite cardiometabolic risk score after adjustment for race, age, generation and sex. With each additional healthy lifestyle factor, cardiometabolic risk decreased by 31\% (OR 0.69; 95\% CI 0.61, 0.78). A higher healthy lifestyle score was associated with a lower prevalence of cardiometabolic risk ( $P$ for trend $<0 \cdot 001$ ). Compared with individuals having $0-1$ healthy lifestyle behaviours, those with 5 or 6 healthy lifestyle behaviours had a $70 \%$ lower prevalence of cardiometabolic risk (OR 0.30; $95 \%$ CI 0.13, 0.67). Healthy lifestyle behaviours including sufficient fruit and vegetable intake, less meat intake, less TV viewing time, abstinence from smoking, modest alcohol intake and regular exercise are associated with reduced cardiometabolic risk.

\section{Key words: Lifestyle: Cardiometabolic risk: Cross-sectional studies}

Cardiometabolic risk is an umbrella term encompassing risk factors for CVD and type 2 diabetes, including increased TAG, fasting glucose, blood pressure, abdominal obesity and reduced HDL-cholesterol ${ }^{(1)}$. An estimated seventy-six million US adults ${ }^{(2)}$ and $2 \cdot 9$ million adolescents of 12-19 years of age ${ }^{(3)}$ have the metabolic syndrome and the presence of any three of the above-mentioned five factors. The National Cholesterol Education Program Adult Treatment Panel III guidelines also include elevated LDL-cholesterol in its definition of the metabolic syndrome $^{(4)}$. A previous study has identified the metabolic syndrome as a significant predictor of the development of CVD and type 2 diabetes $^{(5)}$. Similarly, the Framingham Risk Score, which includes age, sex, cigarette smoking and the above-mentioned factors, was found to be associated with CHD and stroke ${ }^{(6)}$.

Metabolic, clinical and epidemiological studies have examined the influence of individual dietary and lifestyle factors on adverse cardiometabolic outcomes, showing that diets characterised by high polyunsaturated fat, low glycaemic index or glycaemic load, and increased consumption of fish, fruits, vegetables, nuts and whole grains appear to reduce the risk of cardiometabolic diseases ${ }^{(7)}$. Furthermore, increased television (TV) viewing time ${ }^{(8-10)}$, psychosocial stressors $^{(11,12)}$, cigarette smoking ${ }^{(13,14)}$, and both excessive drinking and abstinence from alcohol ${ }^{(15)}$ were associated with increased cardiovascular risk and mortality.

Healthy dietary and lifestyle patterns tend to co-exist and inter-relate with each other; therefore, it is important to examine dietary and lifestyle factors as a whole. However, only minimal data are available regarding the cumulative effects of healthy lifestyle behaviours on cardiometabolic risk. Stampfer et al. ${ }^{(16)}$ examined the effect of a combination of modifiable factors including smoking, alcohol drinking, physical activity, BMI and diet on the risk of CHD among 84129 women in the Nurses' Health Study. The outcome of interest was major coronary events which occurred rarely among subjects within the low-risk categories, making it hard to provide reliable estimates of the effects ${ }^{(16)}$. A few studies have identified diet and lifestyle behaviours associated with the risk of heart failure ${ }^{(17)}$ and hypertension ${ }^{(18)}$, but the effect of these behaviours on

Abbreviations: LRC, Lipid Research Clinic; MVPA, moderate to vigorous physical activity; PFS, Princeton Follow-up Study; TV, television. 
the clustering of cardiometabolic risk factors (rather than the actual disease) has not been evaluated.

The present study was based on a population-based, crosssectional sample from the Lipid Research Clinic (LRC)'s Princeton Follow-up Study (PFS) to examine the effect of a combination of lifestyle behaviours (including fruit and vegetable intake, meat intake, smoking, alcohol consumption, physical activity and TV viewing time) on cardiometabolic risk reduction.

\section{Methods}

\section{Study population}

The analysis was based on 1454 participants from the PFS (1998-2003) who were followed up from the National Heart, Lung and Blood Institute LRC Prevalence Study in Cincinnati (1973-8). A detailed description of the LRC and PFS has been published elsewhere ${ }^{(19-21)}$. Briefly, the LRC was a multi-centre, multi-stage epidemiological study of lipids in eleven different populations in the USA and Canada. The LRC study in Cincinnati examined about 7000 students in grades $1-12$ and 4500 parents in the Princeton School District. A family identification number was used to identify the familial correlation among parents and children from the same family. Stage 1 measured total cholesterol and TAG in all subjects plus demographic data. Stage 2 measured lipid profiles, blood pressure, BMI, triceps skinfolds, $24 \mathrm{~h}$ diet recalls, family history of CVD and twelve-channel clinical chemistries in random and hyperlipidaemic subsets of all stage 1 subjects. Stage 3 repeated stage 2 measures in all first-degree relatives of random and hyperlipidaemic index cases from stage 2, except for blood pressure.

After an average 26 years since their initial participation in the LRC study, eligible former schoolchildren were invited to participate in the PFS along with a sibling or a parent to assess the changes in lifestyles and cardiometabolic risk factors ${ }^{(19-21)}$. Among the 1454 PFS participants, $26 \%$ were black and $56 \%$ were female. There were 432 parents (age 66.5 (SD 6.6) years) and 1022 adult children (age 39.6 (SD 4.9) years).

The study was conducted according to the guidelines laid down in the Declaration of Helsinki, and all procedures involving human subjects were approved by the Cincinnati Children's Hospital institutional review board. Written informed consent was obtained from all subjects. The University of Massachusetts Boston institutional review board approved the data analysis protocol.

\section{Measures and definitions of healthy lifestyle and} cardiometabolic risk in the Princeton Follow-up Study

Participants were assessed for sociodemographic characteristics, smoking, alcohol use, medical history and family history of certain diseases using standardised self-administered questionnaires. Dietary intake was measured by a Block-Quantified Food Frequency questionnaire. Information on physical activity was collected through a $7 \mathrm{~d}$ physical activity recall using the Paffenbarger Physical Activity Questionnaire, which had been validated against pedometer readings, treadmill tests and $\mathrm{VO}_{2 \max }{ }^{(22-24)}$. Participants' weight, height, waist circumference, blood pressure, LDL-cholesterol, HDL-cholesterol, total cholesterol, TAG, glucose and insulin were measured following standard procedures ${ }^{(25)}$.

Diet measures chosen for inclusion in the present study were daily servings of meat, vegetables and fruits. Lifestyle factors were smoking (never/ever smoker), alcohol use (number of alcoholic beverages per week), physical activity (hours of moderate to vigorous physical activity (MVPA) per week) and TV viewing hours per d. Each of these six lifestyle factors has a substantial research base indicating potential reduction in cardiometabolic risk $^{(6-9,12-17)}$.

Healthy lifestyle behaviour was defined based on public health recommendations and evidence from the previous literature on associations between individual lifestyle factors and cardiometabolic diseases. For fruit and vegetable intake, the Food Pyramid developed by the US Department of Agriculture recommends 3-5 servings of vegetables and $2-4$ servings of fruits each day ${ }^{(26)}$; therefore, a healthy behaviour for fruit and vegetable intake was defined as $\geq 5$ servings/d. Because the Food Pyramid recommends $2-3$ servings of meat daily ${ }^{(26)}$, we defined a healthy behaviour for meat intake as $\leq 2$ servings/d. The cut-off points for smoking status, alcohol consumption, TV viewing time and MVPA time were determined based on the findings from previous studies ${ }^{(9,15,17)}$. For example, the healthy alcohol drinking behaviour was defined as at least $1-2$ drinks/week. This is based on the finding that compared with non-drinkers $(<1$ drink/week), regular drinkers had a decreased risk of ischaemic stroke ${ }^{(15)}$. For TV viewing time, subjects with TV viewing time $<2 \mathrm{~h} / \mathrm{d}$ had a lower CVD mortality compared with those with more than $2 \mathrm{~h} / \mathrm{d}$; therefore, $\leq 2 \mathrm{~h}$ TV viewing time was defined as a healthy behaviour ${ }^{(9)}$. For physical activity, previous studies found that at least $30 \mathrm{~min}$ of MVPA/d, corresponding to $3.5 \mathrm{~h} /$ week, was associated with a reduction in the risk of CHD and stroke ${ }^{(15,17)}$. The MVPA data in the present study were recorded in integers; therefore, we used $4 \mathrm{~h} /$ week as our cut-off point. We tested these cut-off points in exploratory data analysis, and found consistent relationships between each healthy lifestyle behaviour, as defined above, and cardiometabolic risk reduction. A combination of healthy lifestyle behaviours included daily fruit and vegetable intake $\geq 5$ servings, daily meat intake $\leq 2$ servings, never smoking, consuming 2-6 alcoholic drinks/week, TV viewing $\leq 2 \mathrm{~h} / \mathrm{d}$ and MVPA $\geq 4 \mathrm{~h} /$ week. The presence of each behaviour was given a score of 1 , so the healthy lifestyle score ranged from 0 to 6. 
The primary outcome, cardiometabolic risk, was defined as having at least three of the following conditions: BMI $\geq 25 \mathrm{~kg} / \mathrm{m}^{2}$, waist circumference $\geq 102 \mathrm{~cm}$ among men or $\geq 88 \mathrm{~cm}$ among women, blood pressure $\geq 130 / 85 \mathrm{mmHg}$ or use of medication for hypertension; fasting blood glucose $\geq 1000 \mathrm{mg} / \mathrm{l}$ or use of glucose-lowering medication, total cholesterol $\geq 2000 \mathrm{mg} / 1$ LDL-cholesterol $\geq 1300 \mathrm{mg} / \mathrm{l}$, total $\mathrm{TAG} \geq 1500 \mathrm{mg} / \mathrm{l}$ or drug treatment for elevated total TAG; and HDL-cholesterol $<400 \mathrm{mg} / 1$ in men or $<500 \mathrm{mg} / 1$ in women or drug treatment for reduced HDL-cholesterol. The cardiometabolic risk measures were based on recommendations from the Adult Treatment Panel III, the American Heart Association/National Heart, Lung and Blood Institute and the International Diabetes Federation $^{(4,27,28)}$. The secondary outcome of the present study was the composite cardiometabolic risk score, defined as an individual's total number of risk factors. This score varied between 0 and 9 .

\section{Statistical analyses}

Means and standard deviations were calculated for continuous variables; numbers and proportions were calculated for categorical variables. A mixed-effect generalised linear regression model was used to evaluate associations of individual lifestyle factors with cardiometabolic risk in univariate analyses adjusted for within-family correlation identified by the same family identification number. Covariates including age, sex, race and generation were added to the model in multivariate analyses. OR and 95\% CI were obtained.

Next, each healthy lifestyle factor and the global healthy lifestyle score were examined as predictors of the presence/absence of cardiometabolic risk. The variables for individual healthy lifestyle factors were dichotomous (yes/no). The healthy lifestyle score was initially treated as a continuous variable, but only $1.2 \%$ (eighteen) of the subjects had a healthy lifestyle score of 0 , and only $2.6 \%$ (thirty-eight) and $0.07 \%$ (one) had scores of 5 or 6 . Consequently, we collapsed the data into five groups to achieve robust sample sizes at the extremes: 0-1 as the reference group, 2, 3, 4 and 5-6. Four dummy variables were created for the five groups of the global healthy lifestyle score. An ordinal score was given to each category of the healthy lifestyle score, and then an analysis of $P$ for a trend test was performed to examine the trend of cardiometabolic risk with increasing healthy lifestyle scores. Coefficients were obtained using the mixed-effect logistic regression because the outcome, cardiometabolic risk, was a binary variable.

We then used the composite score of cardiometabolic risk (i.e. the number of cardiometabolic risks) as the outcome variable. The composite score was categorised into four groups: 0-2 (reference group), 3-4, 5-6 and 7-9, so that each group had a similar sample size. Since the outcome was ordinal, the mixed-effect ordered logistic regression was used to model the likelihood of having 3-4 cardiometabolic risk factors, 5-6 cardiometabolic risk factors and 7-9 cardiometabolic risk factors, $v$. having 0-2 cardiometabolic risk factors (the reference group), on individual healthy lifestyle factors and then on the healthy lifestyle score, after adjustment for age, sex, race, generation and within-family correlation.

All $P$ values were two-sided, and the significance level was set at 0.05. Data were analysed with Statistical Analysis Software version 9.1 (SAS Institute, Cary, NC, USA).

\section{Results}

Table 1 summarises the prevalence of cardiometabolic risk according to demographic characteristics of the study population. Overall, $50 \cdot 9 \%$ (740 out of 1454) of the subjects had cardiometabolic risk. Males (53\%) and females (49.3\%) had a similar prevalence of cardiometabolic risk, as did Blacks (52.8\%) and Whites (50.2\%) (all $P$ values $>0.05$ ). First-generation participants (parents) had a higher prevalence of cardiometabolic risk compared with their children, 66.9\% (289 out of 432) in parents $v .44 \cdot 1 \%$ (451 out of 1022$)$ in their children $(P<0 \cdot 001)$. Within generation, age was positively associated with cardiometabolic risk.

The univariate and multivariate analyses of associations between individual lifestyle factors and cardiometabolic risk are summarised in Table 2. Daily fruit intake and frequency of alcohol consumption were associated with a

Table 1. Prevalence of cardiometabolic risk* by demographic characteristics (Number of participants and percentage or mean values and standard deviations)

\begin{tabular}{|c|c|c|c|c|c|}
\hline \multirow{3}{*}{$\begin{array}{l}\text { Demographic } \\
\text { characteristics }\end{array}$} & \multicolumn{4}{|c|}{ Having cardiometabolic risk } & \multirow[b]{3}{*}{$P$} \\
\hline & \multicolumn{2}{|c|}{ Yes } & \multicolumn{2}{|c|}{ No } & \\
\hline & $n$ & $\%$ & $n$ & $\%$ & \\
\hline \multicolumn{6}{|l|}{ Sex } \\
\hline Male $(n 642)$ & 340 & 53.0 & 302 & $47 \cdot 0$ & \multirow[t]{2}{*}{0.16} \\
\hline Female ( $n$ 812) & 400 & $49 \cdot 3$ & 412 & $50 \cdot 7$ & \\
\hline \multicolumn{6}{|l|}{ Race } \\
\hline White ( $n$ 1081) & 543 & $50 \cdot 2$ & 538 & $49 \cdot 8$ & \multirow[t]{2}{*}{0.39} \\
\hline Black ( $n$ 373) & 197 & $52 \cdot 8$ & 176 & $47 \cdot 2$ & \\
\hline \multicolumn{6}{|l|}{ Generation } \\
\hline Parent ( $n$ 432) & 289 & $66 \cdot 9$ & 143 & $33 \cdot 1$ & \multirow[t]{2}{*}{$<0.001$} \\
\hline Child ( $n$ 1022) & 451 & 44.1 & $57 \cdot 1$ & $55 \cdot 9$ & \\
\hline \multicolumn{5}{|c|}{ Age of parent participants ( $n$ 432) (years) } & \multirow[t]{3}{*}{$<0.001$} \\
\hline Mean & $68 \cdot 0$ & $65 \cdot 7$ & & & \\
\hline SD & 6.5 & $6 \cdot 6$ & & & \\
\hline \multicolumn{5}{|c|}{ Age of child participants ( $n$ 1022) (years) } & \multirow[t]{3}{*}{0.007} \\
\hline Mean & $40 \cdot 1$ & 39.2 & & & \\
\hline SD & $5 \cdot 0$ & 4.8 & & & \\
\hline
\end{tabular}

* Cardiometabolic risk was defined as having at least three of the following conditions: $\mathrm{BMI} \geq 25 \mathrm{~kg} / \mathrm{m}^{2}$, waist circumference $\geq 102 \mathrm{~cm}$ among men or $\geq 88 \mathrm{~cm}$ among women, blood pressure $\geq 130 / 85 \mathrm{mmHg}$ or use of medication for hypertension; fasting blood glucose $\geq 1000 \mathrm{mg} / \mathrm{l}$ or use of glucose-lowering medication, total cholesterol $\geq 2000 \mathrm{mg} / \mathrm{l}$, LDL-cholesterol $\geq 1300 \mathrm{mg} / \mathrm{l}$, tota $\mathrm{TAG} \geq 1500 \mathrm{mg} / \mathrm{l}$ or drug treatment for elevated total TAG; and HDLcholesterol $<400 \mathrm{mg} / \mathrm{l}$ in men or $<500 \mathrm{mg} / \mathrm{l}$ in women or drug treatment for reduced $\mathrm{HDL}$-cholesterol. 
Table 2. Reductions and increases in cardiometabolic risk associated with individual lifestyle factors (Odds ratios and $95 \%$ confidence intervals)

\begin{tabular}{|c|c|c|c|c|c|c|}
\hline \multirow[b]{2}{*}{ Lifestyle factors } & \multicolumn{3}{|c|}{ Crude } & \multicolumn{3}{|c|}{ Adjusted $\ddagger$} \\
\hline & OR & $95 \% \mathrm{Cl}$ & $P$ & OR & $95 \% \mathrm{Cl}$ & $P$ \\
\hline Fruit intake (servings/d) & 0.91 & $0.81,1.01$ & 0.09 & 0.85 & $0.73,0.99$ & $0.04^{\star}$ \\
\hline Vegetable intake (servings/d) & 1.01 & $0.96,1.06$ & 0.67 & $1 \cdot 00$ & $0.93,1.07$ & 0.94 \\
\hline Meat intake (servings/d) & $1 \cdot 11$ & $1 \cdot 02,1 \cdot 20$ & $0 \cdot 01^{*}$ & $1 \cdot 13$ & $1 \cdot 01,1 \cdot 26$ & $0.03^{*}$ \\
\hline Cigarette smoking (ever $v$. never) & $1 \cdot 24$ & $0.95,1.64$ & 0.12 & 1.42 & $1 \cdot 01,2 \cdot 01$ & $0.04^{*}$ \\
\hline Alcohol drinking (frequency/week) & 0.90 & $0.83,0.98$ & $0 \cdot 01^{*}$ & 0.85 & $0.77,0.94$ & $0.001^{*}$ \\
\hline Physical activity (h/week) & 0.85 & $0 \cdot 62,1 \cdot 15$ & $0 \cdot 28$ & $1 \cdot 00$ & $0.99,1.01$ & 0.58 \\
\hline TV viewing $(\mathrm{h} / \mathrm{d})$ & $1 \cdot 26$ & $1 \cdot 16,1 \cdot 36$ & $<0.001^{*}$ & $1 \cdot 19$ & $1 \cdot 08,1 \cdot 31$ & $<0.001^{*}$ \\
\hline
\end{tabular}

decreased prevalence of cardiometabolic risk after adjusting for sex, age, race and generation, whereas daily meat intake, cigarette smoking and TV viewing time were associated with increased cardiometabolic risk (Table 2).

Then, each lifestyle factor was categorised dichotomously, generating six healthy lifestyle factors, including high fruit and vegetable consumption ( $\geq 5$ servings/d), low meat consumption ( $\leq 2$ servings/d), never smoking, consuming alcohol regularly (2-6 drinks/week), regularly participating in MVPA ( $\geq 4 \mathrm{~h} /$ week) and less TV viewing $(\leq 2 \mathrm{~h} / \mathrm{d})$. About a third ( 437 out of 1454 or $30 \cdot 1 \%$ ) of the participants had 2 healthy lifestyle behaviours, and $40.6 \%$ (590 out of 1454) and $15.5 \%$ (226 out of 1454) had 3 and 4 healthy lifestyle behaviours, respectively. The remaining 162 subjects $(11 \cdot 1 \%)$ had 0 or 1 healthy lifestyle behaviour, and $39(2 \cdot 7 \%)$ had 5 or 6 healthy lifestyle behaviours. As shown in Table 3, in the univariate model adjusted for the intra-cluster correlation within family, low meat consumption (OR 0.77; 95\% CI 0.61, 0.96), regular consumption of alcohol (OR 0.66; $95 \%$ CI 0.52, 0.83), regularly participating in MVPA (OR $0.80 ; 95 \%$ CI 0.63 , $1 \cdot 00$ ) and less TV viewing time (OR $0 \cdot 42 ; 95 \%$ CI $0 \cdot 23$, $0.78)$ were inversely associated with cardiometabolic risk. These factors remained significant in multivariate analyses after adjustment for race, age, generation and sex, except for physical activity which became marginally significant. In addition, high fruit and vegetable consumption (OR $0.71 ; 95 \%$ CI $0.55,0.93$ ) and never smoking (OR 0.69; $95 \%$ CI $0.51,0.92)$ were also inversely associated with cardiometabolic risk.

Next, we examined the healthy lifestyle score, which was the sum of the six healthy lifestyle factors. Fig. 1 shows that with each increment of the healthy lifestyle score, the prevalence of cardiometabolic risk decreased on average by $31 \%$ (OR 0.69; $95 \%$ CI 0.61, 0.78). A linear trend was observed. Compared with individuals having $0-1$ healthy lifestyle score, those with 3 healthy lifestyle behaviours had a $47 \%$ lower prevalence of cardiometabolic risk (OR $0.53 ; 95 \%$ CI $0.36,0.78$ ), those with 4 healthy lifestyle behaviours had a $68 \%$ lower cardiometabolic risk (OR 0.32; $95 \% \mathrm{CI} 0 \cdot 20,0.51$ ), and those with 5 or 6 healthy lifestyle behaviours had a $70 \%$ lower risk (OR 0.30; 95\% CI 0.13, 0.67). A higher healthy lifestyle score was associated with a lower prevalence of cardiometabolic risk ( $P$ for trend $<0 \cdot 001$ ).

Table 4 presents results from the ordered logistic regression on the association between healthy lifestyle factors and the composite score of cardiometabolic risk, which are further visualised in Fig. 2. There were statistically significant inverse relationships between the presence

Table 3. Reductions in cardiometabolic risk associated with individual lifestyle factors

(Odds ratios and $95 \%$ confidence intervals)

\begin{tabular}{|c|c|c|c|c|c|c|}
\hline \multirow[b]{2}{*}{ Healthy lifestyle factors } & \multicolumn{3}{|c|}{ Crude } & \multicolumn{3}{|c|}{ Adjusted $\ddagger$} \\
\hline & OR & $95 \% \mathrm{Cl}$ & $P$ & OR & $95 \% \mathrm{Cl}$ & $P$ \\
\hline$\geq 5$ Servings of fruits and vegetables/d & 0.87 & $0.68,1 \cdot 11$ & 0.27 & 0.71 & $0.55,0.93$ & $0.01^{*}$ \\
\hline$\leq 2$ Servings of meat/d & 0.77 & $0.61,0.96$ & $0.02^{*}$ & 0.69 & $0.54,0.89$ & $0.004^{*}$ \\
\hline Never smoking & 0.80 & $0.61,1.59$ & $0 \cdot 12$ & 0.69 & $0.51,0.92$ & $0.01^{\star}$ \\
\hline 2-6 Alcohol drinks/week & 0.66 & $0.52,0.83$ & $<0.001^{*}$ & 0.62 & $0.48,0.80$ & $<0.001^{*}$ \\
\hline$\geq 4 \mathrm{~h} \mathrm{MVPA} /$ week & 0.80 & $0.63,1.00$ & $0.05^{\star}$ & 0.81 & $0.63,1.03$ & 0.08 \\
\hline$\leq 2 \mathrm{~h}$ TV watching/d & 0.42 & $0.23,0.78$ & $0.01^{*}$ & 0.44 & $0.23,0.85$ & $0.01^{*}$ \\
\hline Global healthy lifestyle score & 0.71 & $0.64,0.79$ & $<0.001^{*}$ & 0.69 & $0.61,0.78$ & $<0.001^{*}$ \\
\hline
\end{tabular}

MVPA, moderate to vigorous physical activity; TV, television.

${ }^{\star} P<0.05$

$\dagger$ Adjusted for intra-cluster correlation within family.

‡ Adjusted for age, race, sex, generation and intra-cluster correlation within family. 


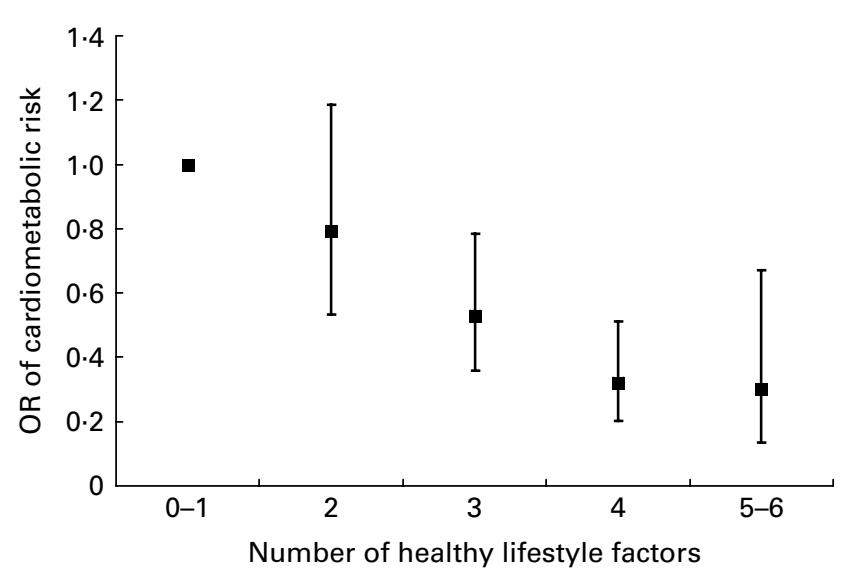

Fig. 1. Linear trend between the global healthy lifestyle score and cardiometabolic risk.

of healthy lifestyle behaviours and cardiometabolic risk score. For example, individuals who consumed alcohol regularly, compared with those who did not, had $27 \%$ lower odds of a composite cardiometabolic risk score of $3-4 v$. 0-2 (OR 0.73; 95\% CI 0.54, 0.98), and the protective effect of alcohol consumption increased as the cardiometabolic risk score increased. The findings were similar for the healthy lifestyle score. With every increment in healthy lifestyle score, the odds of a cardiometabolic risk score of 3-4 v. 0-2 were $18 \%$ lower (OR 0.82; $95 \%$ CI $0.72,0.95$ ), the odds of having the score as 5-6v $0-2$ were $32 \%$ lower (OR 0.68; 95\% CI 0.59, 0.79), and the odds of having the score as 7-9 v. 0-2 were 36\% lower (OR 0.64; 95\% CI $0.53,0.78)$.

\section{Discussion}

Results from the present study indicated that a combination of healthy lifestyle factors including sufficient fruit and vegetable intake, less meat intake, abstinence from smoking, moderate drinking, regular exercise and less TV viewing time was associated with a decreased cardiometabolic risk. Each additional healthy lifestyle factor was associated with a $31 \%$ reduction in cardiometabolic risk. Cardiometabolic risk decreased in a graded manner as the number of healthy lifestyle factors increased. These results support the hypothesis that reductions in cardiometabolic risk are associated with both individual and cumulative adherence to healthy lifestyle behaviours ${ }^{(29)}$. When individual lifestyle factors were examined individually, most, but not all, factors were associated with cardiometabolic risk reduction.

The lifestyle factors in the present study have been examined individually or jointly by other researchers, and the present study adds to this literature by focusing on precursors to the actual disease rather than on frank disease outcomes as has typically been the case. For example, Chiuve et al. ${ }^{(30)}$ found that a low-risk lifestyle including healthy diet, not smoking, alcohol consumption $5-30 \mathrm{~g} / \mathrm{d}, \quad \mathrm{MVPA} \geq 30 \mathrm{~min} / \mathrm{d}$ and maintaining $\mathrm{BMI}<25 \mathrm{~kg} / \mathrm{m}^{2}$ resulted in a $62 \%$ reduction in $\mathrm{CHD}$ among men of middle age or later in life. Djoussé et $a l .{ }^{(17)}$ found that a combination of $\mathrm{BMI}<25 \mathrm{~kg} / \mathrm{m}^{2}$, not smoking, exercise $\geq 5$ times/week, alcohol intake $\geq 5$ drinks/week, breakfast cereal $\geq 1$ serving/week and fruits and vegetables $\geq 1$ serving/week reduced the risk of heart failure. In another study, adherence to the Mediterranean diet, no smoking and exercise were associated with reduced total cholesterol, LDL-cholesterol and $\mathrm{TAG}^{(31)}$. In addition, several studies have documented the effects of other lifestyle factors such as folic acid supplementation $^{(18,32,33)}$, dairy consumption ${ }^{(34)}$, whole-grain intake $^{(35)}$ and psychosocial stressors ${ }^{(36)}$. To the best of our knowledge, no studies have examined the effect of a combination of healthy lifestyle factors on cardiometabolic risk, which is a precursor of CVD and type 2 diabetes $^{(37)}$. By targeting lifestyle behaviours associated with cardiometabolic risk, we can prevent and manage risk for cardiometabolic disease and adverse outcomes of these disease processes at the early stages of development.

The present study found that fruit and vegetable intakes, when viewed on a continuous scale, were not significantly associated with cardiometabolic risk, whereas a high intake of fruits and vegetables ( $\geq 5$ servings/d) was associated

Table 4. Associations between individual healthy lifestyle factors, global healthy lifestyle score and the composite score of cardiometabolic risk (Odds ratios and $95 \%$ confidence intervals)

\begin{tabular}{|c|c|c|c|c|c|c|}
\hline \multirow[b]{3}{*}{ Healthy lifestyle factors } & \multicolumn{6}{|c|}{ Composite cardiometabolic risk score } \\
\hline & \multicolumn{2}{|c|}{ Score $=3-4$ v. $0-2$} & \multicolumn{2}{|c|}{ Score $=5-6$ v. $0-2$} & \multicolumn{2}{|c|}{ Score $=7-9$ v. $0-2$} \\
\hline & Adjusted OR $\dagger$ & $95 \% \mathrm{Cl}$ & Adjusted OR $†$ & $95 \% \mathrm{Cl}$ & Adjusted OR $†$ & $95 \% \mathrm{Cl}$ \\
\hline$\geq 5$ Servings of fruits and vegetables/d & $0.73^{\star}$ & $0.54,0.99$ & $0.69^{*}$ & $0.50,0.96$ & $0.56^{\star}$ & $0.36,0.88$ \\
\hline$\leq 2$ Servings of meat/d & 0.75 & $0.57,1.01$ & $0.67^{*}$ & $0.49,0.90$ & $0.55^{*}$ & $0.37,0.83$ \\
\hline Never smoking & $1 \cdot 10$ & $0.78,1.55$ & 0.76 & $0.53,1.08$ & 0.74 & $0.46,1.17$ \\
\hline 2-6 Alcohol drinks/week & $0.73^{\star}$ & $0.54,0.98$ & $0.60^{*}$ & $0.44,0.83$ & $0.47^{*}$ & $0.30,0.73$ \\
\hline$\geq 4 \mathrm{~h} \mathrm{MVPA} /$ week & 0.88 & $0.66,1.17$ & 0.76 & $0.56,1.04$ & 0.99 & $0.65,1.50$ \\
\hline$\leq 2 \mathrm{~h}$ TV watching/d & 0.84 & $0.44,1.60$ & $0.35^{\star}$ & $0.14,0.86$ & 0.40 & $0.12,1.41$ \\
\hline Global healthy lifestyle score & $0.82^{*}$ & $0.72,0.95$ & $0.68^{*}$ & $0.59,0.79$ & $0.64^{*}$ & $0.53,0.78$ \\
\hline
\end{tabular}

MVPA, moderate to vigorous physical activity; TV, television.

${ }^{\star} P<0.05$.

$\dagger$ Adjusted for age, race, sex, generation and intra-cluster correlation within family. 


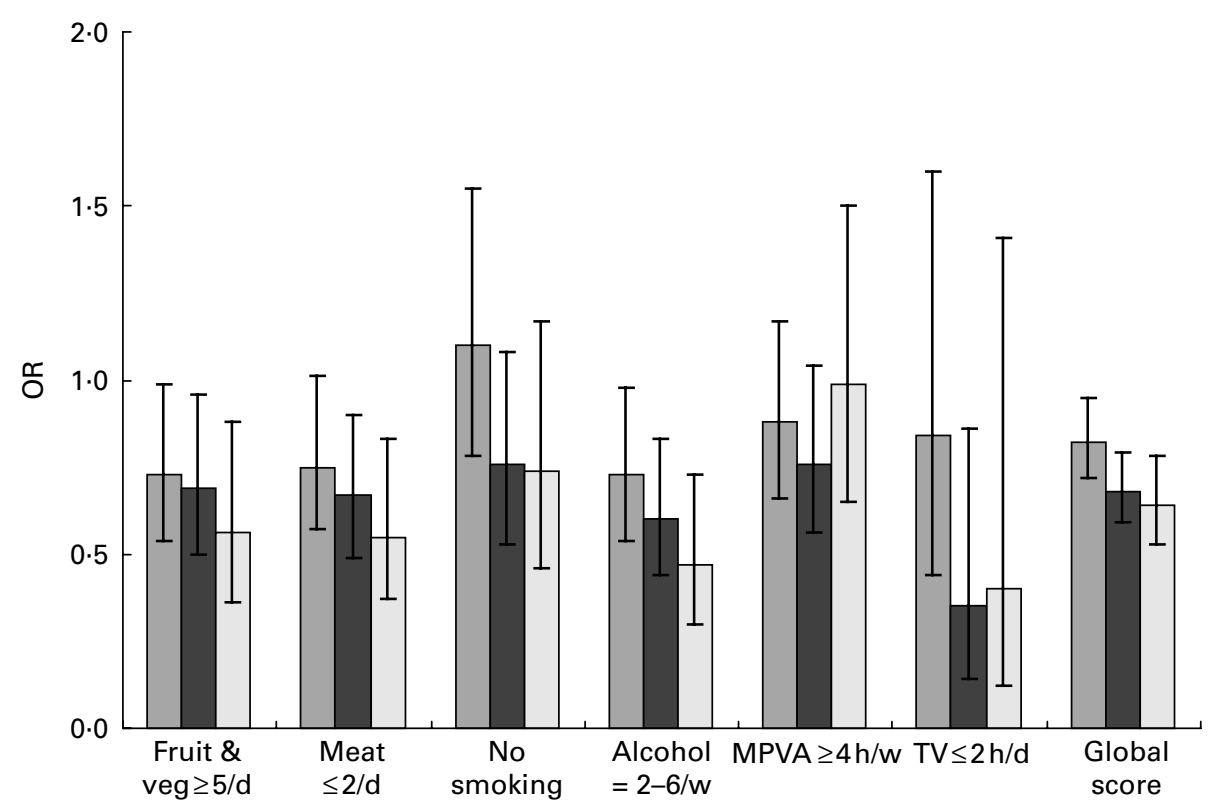

Fig. 2. Associations between healthy lifestyle factors and composite score of cardiometabolic risk. $\square$, OR of the cardiometabolic risk composite score 3-4 v. 0-2; $\square$, OR of the cardiometabolic risk composite score 5-6 v. 0-2; $\square$, OR of the cardiometabolic risk composite score 7-9 v. 0-2. Veg, vegetables; w, weeks; MVPA, moderate to vigorous physical activity; TV, television.

with reduced cardiometabolic risk. This suggests a possible threshold effect of fruit and vegetable consumption on cardiometabolic health. The present findings are consistent with the results of a previous epidemiological study, which found a similar protective effect of a high fruit and vegetable intake. For example, in a study in the USA, compared with people consuming $<3$ servings of fruits and vegetables per $d$, those consuming 5-7 servings per $\mathrm{d}$ had a $73 \%$ lower risk for myocardial infarction ${ }^{(38)}$. A study in India found that people consuming 3.5 servings of vegetables per $d$ had a threefold lower risk of IHD than did those consuming 0.8 servings $/ \mathrm{d}^{(39)}$.

Strengths of the present study include the populationbased dataset, the objective measurement of cardiometabolic risk and the robustness of the results from different analyses. Healthy lifestyle factors were tested individually and jointly as a composite healthy lifestyle score, while the outcome, cardiometabolic risk, was measured both dichotomously and as a composite risk score. The results were largely consistent across the analyses, corroborating the evidence of the effect of a healthy lifestyle on cardiometabolic risk. The finding that MVPA was not individually associated with cardiometabolic risk reduction and showed no discernible dose-response pattern is surprising in the light of substantial literature to the contrary and may indicate a low validity of the MVPA data (see later for further discussion on a possible recall error in physical activity data). The absence of a statistically significant effect of cigarette smoking, conversely, probably reflects the sample size given the width of the CI.

The study is limited, however, by the cross-sectional design, which does not allow us to establish the time sequence of exposure and outcome, therefore preventing us from inferring causality. The selection bias in the cross-sectional design may also affect the estimated associations from the present study. Participants with a very unhealthy lifestyle and lethal cardiometabolic outcomes may not be included in the study, which is likely to lead to an underestimation of the effect of the lifestyle factors on cardiometabolic risk. A prospective, longitudinal study is desired to obtain more conclusive evidence on the temporal relationship between lifestyle and cardiometabolic risk.

Physical activity was measured by $7 \mathrm{~d}$ physical activity recall using the Paffenbarger Physical Activity Questionnaire in the present study ${ }^{(22)}$. Physical activity is a complex behaviour with four major components, frequency, intensity, duration and mode, which makes it difficult to obtain accurate measurement of all these components ${ }^{(40)}$. The $7 \mathrm{~d}$ recall method is practical and feasible for administering to large populations of individuals; however, due to its subjective nature in methodology, it is subject to recall error and unable to quantify physical activity with sufficient accuracy and precision. When compared with the doubly labelled water method, which is the criterion method to evaluate physical activity-related energy expenditure, this $7 \mathrm{~d}$ recall method has a low accuracy in the estimation of physical activity-related energy expenditure for individuals under free-living conditions. In addition, it is imprecise with an underestimation of physical activityrelated energy expenditure in the most-active individuals and an overestimation in the least-active individuals ${ }^{(41)}$. It was found that MVPA was not individually associated with cardiometabolic risk reduction in the present study, indicating a low validity of the MVPA data measured by the $7 \mathrm{~d}$ recall method. 
Another limitation of the present study is that some potential confounders such as education and income plus unknown confounders were not adjusted for, so a potential confounding effect could not be ruled out. Future study should use a longitudinal study design to examine the impacts of lifestyle in early life on cardiometabolic risk in later life. In addition, diet appears to be important for cardiometabolic risk in the present study, but we used only three aspects of dietary intake - fruits, vegetables and meat. Other dietary components such as total energy intake, fat, sugar, fibre intake, etc., which may influence CVD risk, were not included in the analyses.

Results from the present study provide further evidence supporting the beneficial effect of healthy lifestyle behaviours on cardiometabolic risk. It has important public health implications regarding the prevention of cardiometabolic disease.

\section{Acknowledgements}

L. S., J. A. M., J. W. and L. L. H. designed the study; L. S. performed the statistical analyses and wrote the manuscript; M. H. conducted the literature review; J. A. M., L. L. H. and J. W. edited the manuscript and helped with the interpretation and discussion of results. All authors approved the final manuscript. The authors do not have any conflicts of interest. The present study was supported by research grant HL62394 from the National Institutes of Health (J. A. M.) and the Joseph P. Healey from the University of Massachusetts Boston (L. S.).

\section{References}

1. Brunzell J, Davidson M, Furberg C, et al. (2008) Lipoprotein management in patients with cardiometabolic risk: consensus statement from the American Diabetes Association and the American College of Cardiology Foundation. Diabetes Care 31, 811-822.

2. Ford E (2005) Prevalence of the metabolic syndrome defined by the International Diabetes Federation among adults in the U.S. Diabetes Care 28, 2745-2749.

3. Cook S, Auinger P, Li C, et al. (2008) Metabolic syndrome rates in United States adolescents, from the National Health and Nutrition Examination Survey, 1999-2002. J Pediatr 152, $165-170$.

4. Expert Panel on Detection E, and Treatment of High Blood Cholesterol in Adults. Executive summary of the third report of the National Cholesterol Education Program (NCEP) Expert Panel on Detection, Evaluation, and Treatment of High Blood Cholesterol in Adults (Adult Treatment Panel III). (2001) JAMA 285, 2486-2497.

5. Gami A, Witt B, Howard D, et al. (2007) Metabolic syndrome and risk of incident cardiovascular events and death: a systematic review and meta-analysis of longitudinal studies. J Am Coll Cardiol 49, 403-414.

6. Wannamethee S, Shaper A, Lennon L, et al. (2005) Metabolic syndrome vs Framingham Risk Score for prediction of coronary heart disease, stroke, and type 2 diabetes mellitus. Arch Intern Med 165, 2644-2650.
7. Hu F \& Willett W (2002) Optimal diets for prevention of coronary heart disease. JAMA 288, 2569-2578.

8. Katzmarzyk P, Church T, Craig C, et al. (2009) Sitting time and mortality from all causes, cardiovascular disease, and cancer. Med Sci Sports Exerc 41, 998-1005.

9. Manson J, Greenland P, LaCroix A, et al. (2002) Walking compared with vigorous exercise for the prevention of cardiovascular events in women. $N$ Engl J Med 347, 716-725.

10. Dunstan D, Barr E, Healy G, et al. (2010) Television viewing time and mortality. The Australian Diabetes, Obesity and Lifestyle Study (AusDiab). Circulation 121, 384-391.

11. Rugulies R (2002) Depression as a predictor for coronary heart disease a review and meta-analysis. Am J Prev Med 23, 51-61.

12. Wassertheil-Smoller S, Shumaker S \& Ockene J (2004) Depression and cardiovascular sequelae in postmenopausal women. Arch Intern Med 164, 289-298.

13. Mitchell G, Hwang S, Vasan R, et al. (2010) Arterial stiffness and cardiovascular events. The Framingham Heart Study. Circulation 121, 505-511.

14. Tamura U, Tanaka T, Okamura T, et al. (2010) Changes in weight, cardiovascular risk factors and estimated risk of coronary heart disease following smoking cessation in Japanese male workers: HIPOP-OHP Study. J Atheroscler Thromb 17, $12-20$.

15. Kawano Y (2010) Physio-pathological effects of alcohol on the cardiovascular system: its role in hypertension and cardiovascular disease. Hypertens Res 33, 181-191.

16. Stampfer M, Hu F, Manson J, et al. (2000) Primary prevention of coronary heart disease in women through diet and lifestyle. $N$ Engl J Med 343, 16-22.

17. Djoussé L, Driver JA \& Gaziano JM (2009) Relation between modifiable lifestyle factors and lifetime risk of heart failure. JAMA 302, 394-400.

18. Forman JP, Stampfer MJ \& Curhan GC (2009) Diet and lifestyle risk factors associated with incident hypertension in women. JAMA 302, 401-411.

19. Tyroler HA (1980) Epidemiology of plasma high-density lipoprotein cholesterol levels. The Lipid Research Clinics Program Prevalence Study. Introduction. Circulation $\mathbf{6 2}$ IV1-IV3.

20. Morrison J, Kelly K \& Horvitz R (1982) Parent-offspring and sibling lipid and lipoprotein associations during and after sharing of household environments: the Princeton School District Family Study. Metabolism 31, 158-164.

21. Friedman LA, Morrison JA, Daniels SR, et al. (2006) Sensitivity and specificity of pediatric lipid determinations for adult lipid status: findings from the Princeton Lipid Research Clinics Prevalence Program Follow-up Study. Pediatrics 118, 165-172.

22. Paffenbarger R, Wing A \& Hyde R (1978) Physical activity as an index of heart attack risk in college alumni. Am J Epidemiol 108, 161-175.

23. Pereira M, FitzGerald S, Gregg E, et al. (1997) A collection of physical activity questionnaires for health-related research: Paffenbarger physical activity questionnaire. Med Sci Sports Exerc 29, 83-88.

24. Ainsworth B, Leon A, Richardson M, et al. (1993) Accuracy of the college alumnus physical activity questionnaire. J Clin Epidemiol 46, 1403-1411.

25. Laskarzewski P, Morrison J \& Mellies M (1980) Relationships of measurements of body mass to plasma lipoproteins in schoolchildren and adults. Am J Epidemiol 111, 395-406.

26. US Department of Agriculture (2003) The Food Guide Pyramid. http://www.nal.usda.gov/fnic/Fpyr/pmap.htm

27. Grundy S, Cleeman J \& Daniels S (2005) Diagnosis and management of the metabolic syndrome: an American 
Heart Association/National Heart, Lung, and Blood Institute Scientific Statement. Circulation 112, 2735-2752.

28. Alberti K, Zimmet P \& Shaw J (2005) The metabolic syndrome - a new worldwide definition. Lancet 366 , 1059-1062.

29. Lloyd-Jones DM, Hong Y, Labarthe D, et al. (2010) Defining and setting national goals for cardiovascular health promotion and disease reduction: The American Heart Association's strategic impact goal through 2020 and beyond. Circulation 121, 586-613.

30. Chiuve SE, McCullough ML, Sacks FM, et al. (2006) Healthy lifestyle factors in the primary prevention of coronary heart disease among men. Circulation 114, 160-167.

31. Sofi F, Gori A, Marcucci R, et al. (2007) Adherence to a healthful life attenuates lipid parameters among a healthy Italian population. Nutr Metab Cardiovasc Dis 17, 642-648.

32. Mangoni A, Sherwood R \& Swift C (2002) Folic acid enhances endothelial function and reduces blood pressure in smokers: a randomized controlled trial. J Intern Med 252, 497-503.

33. van Dijk R, Rauwerda J, Steyn M, et al. (2001) Long-term homocysteine-lowering treatment with folic acid plus pyridoxine is associated with decreased blood pressure but not with improved brachial artery endothelium-dependent vasodilation or carotid artery stiffness: a 2-year, randomized, placebo-controlled trial. Arterioscler Thromb Vasc Biol 21, 2072-2079.

34. Moore L, Singer M \& Bradlee M (2005) Intake of fruits, vegetables, and dairy products in early childhood and subsequent blood pressure change. Epidemiology 16, 4-11.

35. Liu S, Manson J \& Stampfer M (2000) A prospective study of whole-grain intake and risk of type 2 diabetes mellitus in US women. Am J Public Health 90, 1409-1415.

36. Yusuf S, Hawken S, Ounpuu S, et al. (2004) Effect of potentially modifiable risk factors associated with myocardial infarction in 52 countries (the INTERHEART study): casecontrol study. Lancet 364, 937-952.

37. Wilson PWF, Agostino RBD, Parise H, et al. (2005) Metabolic syndrome as a precursor of cardiovascular disease and type 2 diabetes mellitus. Circulation 112, 3066-3072.

38. Rimm E, Ascherio A, Giovannucci E, et al. (1996) Vegetable, fruit, and cereal fiber intake and risk of coronary heart disease among men. JAMA 175, 447-451.

39. Rastogi T, Reddy K, Vaz M, et al. (2004) Diet and risk of ischemic heart disease in India. Am J Clin Nutr 79, 582-592.

40. Heyward V (2006) Advanced Fitness Assessment and Exercise Prescription, 5th ed. Champaign, IL: Human Kinetics.

41. Leenders N, Sherman W, Nagaraja H, et al. (2001) Evaluation of methods to assess physical activity in free-living conditions. Med Sci Sports Exerc 33, 1233-1240. 